\title{
Geographical distribution and clinical relevance of nontuberculous mycobacteria in Croatia
}

M. Jankovic ${ }^{1}$, M. Samarzija ${ }^{1}$, I. Sabol ${ }^{2}$ M. Jakopovic ${ }^{1}$, V. Katalinic Jankovic ${ }^{3}$, L. Zmak ${ }^{3}$, B. Ticac ${ }^{4}$, A. Marusic $^{5}$, M. Obrovac ${ }^{3}$ and J. van Ingen 6

${ }^{1}$ University Hospital Centre, Department for Respiratory Diseases, University of Zagreb, Medical School, Zagreb, Croatia

${ }^{2}$ Laboratory of Molecular Virology and Bacteriology, Division of Molecular Medicine, Ruder Boskovic Institute, Zagreb, Croatia

${ }^{3}$ Croatian National Institute of Public Health, National Mycobacterial Reference Laboratory, Zagreb, Croatia

${ }^{4}$ University of Rijeka, School of Medicine, Department of Microbiology and Parasitology, Rijeka, Croatia

${ }^{5}$ Poyiclinic „Medikol“, Department of radiology, Zagreb, Croatia

${ }^{6}$ Radboud University Nijmegen Medical Centre, Department of Medical Microbiology, Nijmegen, the Netherlands

Running head: nontuberculous mycobacteria in Croatia

Word count: 2354

Correspondence

Mateja Jankovic, University Hospital Centre Zagreb, Department for Respiratory Diseases, Jordanovac 104, 10000 Zagreb, Croatia; Email: mateja.jankovic@gmail.com

Key words: atypical mycobacteria, epidemiological study, geographical diversity, pulmonary nontuberculous mycobacterial disease, 
Authors have no conflicts of interest that relate to this manuscript. Research was supported by Croatian National Institute of Public Health and University Hospital Centre Zagreb without any additional funding. M. Jankovic, V. Katalinic Jankovic and J. Van Ingen were involved in the design of the study and wrote the manuscript. I. Sabol did the statistical analysis and took part in the preparation of the manuscript. M. Jankovic, M. Samarzija, V. Katalinic Jankovic, M. Jakopovic, Lj. Zmak, and M. Obrovac, A. Marusic and B. Ticac were involved in the data gathering and/or identification of nontuberculous mycobacteria species and took part in the preparation of the manuscript. 


\section{ABSTRACT}

Setting: Clinical relevance of non-tuberculous mycobacteria (NTM) in Croatia is unknown.

Objective: to estimate the isolation rate of NTM, record geographical differences, and assess the burden of pulmonary NTM disease.

Design: nationwide retrospective cohort study on all Croatian residents with NTM isolated by culture in the period from 2006 through 2010. Microbiological criteria of the American Thoracic Society were used to establish a laboratory-based case definition of possible and probable NTM disease.

Results: Out of 1187 people with pulmonary NTM isolates, $8.6 \%$ met the possible and $5.5 \%$ met the probable disease criteria. We estimated an annual incidence of probable pulmonary NTM disease of $0.23 / 100,000$. This estimated annual incidence was $0.35 / 100,000$ in the coastal and 0.17/100,000 in the continental region. Species distribution differed between coastal and continental Croatia. NTM isolation frequency increased over the study period.

Conclusion: Geography plays a role in NTM species distribution and possibly disease. The overall burden of NTM pulmonary disease in Croatia is still low compared to tuberculosis, but is higher in the coastal compared to the continental region.

\section{INTRODUCTION}

Nontuberculous mycobacteria (NTM) encompass all Mycobacterium species other than Mycobacterium tuberculosis complex and Mycobacterium leprae. There are currently more than 140 species of these environmental, mostly opportunistic pathogens [1]. Recently, these organisms have gained increased attention, due to increases in the isolation frequency of NTM [1-5]. This increase is thought to be most pronounced in countries where the incidence of tuberculosis (TB) is declining [1, 6]. The exact epidemiology of pulmonary NTM disease has been difficult to determine because reporting is not mandatory in most countries and identification of true disease is often difficult $[1,7]$. Laboratory based surveillance may be the most cost-effective method for estimating NTM disease burden over time $[8,9]$. A systematic review of NTM epidemiology as well as estimation of disease burden in countries with intermediate TB burden such as Croatia [10] is lacking. In the current study, we have aimed to calculate the population-based NTM isolation frequency, examine geographical differences in species distribution and estimate burden of pulmonary NTM disease in Croatia. 


\section{METHODS}

Study design. We conducted a retrospective cohort study using laboratory data on all Croatian residents with NTM isolated from respiratory samples by culture in the period from 2006 through 2010. Gastric lavages were excluded from further analysis. Only one isolate per individual was taken into account when calculating NTM isolation rate frequency. For disease incidence, we took into account only the first time that defined disease criteria were met. For individuals meeting those criteria, we looked into the data from the year 2005 in order to exclude those with previously isolated NTM from disease incidence calculation. If multiple NTM species were cultivated from samples of one individual, each species was counted as a separate isolate.

Data collection. In Croatia, all NTM isolates are sent to the National Reference Laboratory (NRL) for identification. From the archive of the NRL, we obtained information on every Croatian resident with NTM isolated in the study period. For each isolate, we recorded patient age, address, zip code, specimen collection date and source, and NTM species isolated. By using the zip code, patients were grouped into two larger areas according to the proximity of the sea: coastal and continental region of Croatia. The Croatian population data which included population by region, age and sex, was obtained from The Statistical Office of the European Communities (Eurostat) [11] and was used for crude and age standardized (European standard population) rate estimations.

Identification of NTM: All NTM were identified by molecular methods (GenoType ${ }^{\odot}$ CM/AS; Hain Lifescience, Nehren, Germany) supplemented with phenotypic methods, using previously published guidelines [12]. NTM, unidentifiable to species level, were sent to Supranational Reference Laboratories (Forschungszentrum Borstel, Germany or Emerging Pathogens Institute, Milano, Italy) for further identification by $16 \mathrm{~S}$ rRNA gene sequencing.

Pulmonary NTM disease case definition: Due to the lack of clinical data, we used the American Thoracic Society (ATS), and Infectious Diseases Society of America (IDSA) microbiological criteria [1] to establish a laboratory-based case definition of probable, possible and unlikely NTM disease. We defined possible NTM disease as two positive sputums or one positive bronchial lavage (BAL) or brush. Probable NTM disease was defined as more than two positive sputum samples or one positive BAL/brush and one or more positive sputum samples. 
Data analysis. Microsoft Excel (Microsoft, Redmond, Washington) was used to calculate frequencies, percentages, median age, crude and standardized rates. Chi-square and chi-square test for trend test as well as rate comparisons were done using MedCalc (MedCalc Software, Mariakerke, Belgium).

\section{RESULTS}

During the study period, the total number of samples of pulmonary origin sent to the NRL for analysis decreased from 57209 samples in the year 2006 to 42223 samples in the year 2010. The total numbers of all isolated Mycobacterium spp. (TB and NTM combined), as well as the number of NTM isolates of pulmonary origin, are shown in Figure 1. The average population of Croatia during the study period was $4,437,538$ with two thirds living in the continental region.

\section{Pulmonary isolates}

NRL identified a total of 1710 pulmonary NTM isolates of 24 species from 1187 individuals. Among those 1187 patients, M. gordonae was the most frequent isolate, followed by $M$. xenopi, M. fortuitum, M. terrae and M. avium (Table 1). Over $80 \%$ of all NTM isolates originated from patients in continental Croatia (Table 1). The species distribution differed between coastal and continental Croatia: M. vaccae $(p=0.05), M$. terrae $(p<0.001), M$. fortuitum $(p=0.012), M$. gordonae $(p<0.001)$ and rapidly growing mycobacteria $(R G M)$ as a group $(p=0.003)$ were significantly more frequent in continental Croatia, while M. xenopi $(p<0.001)$, M. lentiflavum $(p<0.001)$ and M. avium $(p<0.001)$ were associated with the coastal region (Figure 2).

Of 1187 patients with NTM isolates, 59\% were men and 41\% were women with median ages of 64 and 66. M. avium was more often found in women $(p=0.031)$, while $M$. xenopi appeared less common in women than in men $(p=0.002)$ (Table 1$)$. Among patients aged $>50$ years, NTM isolation rates were significantly higher in men than in women ( $p<0.001$; Figure 3$)$. After age stratification, the increasing trend of NTM isolation incidence was observed in the population over 50 years of age living in the continental region of Croatia (data not shown). The annual isolation frequency of the most common NTM species (30 or more individual isolates in 5-year period), are shown in Figure 4. 


\section{Pulmonary disease}

The most frequently isolated NTM species that met the defined microbiologic criteria for probable or possible disease are shown in Table 1. Of 1187 patients with NTM pulmonary isolates, $102(8.6 \%)$ and $65(5.5 \%)$ met the possible and probable disease criteria, respectively. Demographic characteristics of these two groups are shown in Table 2. Whereas M. xenopi disease was most frequently seen, clinical relevance (i.e. percentage of patients meeting the criteria for either possible or probable disease, per species) was higher for M. intracellulare (9/23; 60.9\%), M. avium (24/42; 57.1\%), M. kansasii (5/10; $50 \%)$ and $M$. lentiflavum $(2 / 5 ; 40 \%)$. Of the RGM, M. abscessus was noted as having the highest clinical relevance $(8 / 30 ; 26.7 \%)$. When taking into account only isolates meeting the probable disease criteria, the clinical relevance was highest for $M$. kansasii (4/10; 40\%), M. intracellulare (8/23; 34.8\%), M. avium (14/42; 33.3\%) and M. xenopi (21/184; 11.4\%). Clinical relevance of $M$. gordonae isolates was low, with only $1 \%$ of all patients with $M$. gordonae isolates meeting criteria for probable disease.

The overall estimated age-standardised annual incidence of NTM pulmonary disease amounts to $0.60 / 100,000$. Taking into account only the probable disease group, the estimated annual incidence would be $0.23 / 100,000$. The incidence of true pulmonary NTM disease differs between the coastal and continental region of Croatia. The percentage of patients meeting either possible or probable disease criteria was $25.3 \%$ in the coastal region and $11.4 \%$ in the continental region. The percentage of people meeting the probable disease criteria was $14.2 \%$ in the coastal region, compared to only $3.4 \%$ in the continental region. The incidence and prevalence of probable pulmonary NTM disease were $0.35 / 100.000$ and $1.11 / 100,000$ in the coastal region, but only $0.17 / 100,000$ and $0.23 / 100,000$ in the continental region.

After age stratification, $56(86.2 \%)$ of all probable disease cases and $81(79.4 \%)$ of all possible disease cases belonged to the 50+ age group (Table 2). The annual incidence of combined possible and probable disease in the 50+ age group was estimated at 1.69/100,000 with an increasing trend observed over the study period. 


\section{DISCUSSION}

This is the first study showing the isolation frequency of NTM species from pulmonary samples in Croatia and estimating the nationwide pulmonary NTM disease incidence through the use of comprehensive laboratory data. This is also one of the rare studies on NTM incidence in a country with intermediate TB burden. Croatia's TB incidence rates were 26/100,000 and 17/100,000 in 2006 and 2010 [10].

Pulmonary isolates

The NTM species distribution differed between the coastal and continental region. An increase in NTM isolation frequency was observed for the study period with a peak in the year 2009. This increase was mostly based on increased isolation of $M$. gordonae and M. fortuitum (Figure 3), and a peak in 2009 could be explained by a subsequently established contamination of tap water (presumably consumed by patients before giving sputum sample) with $M$. gordonae in a single centre (V. Katalinic Jankovic, personal communication). Furthermore, the increasing trend of NTM isolation frequency was observed only in the population over 50 years of age living in the continental region of Croatia (data not shown). This increase thus involves mainly clinically irrelevant isolates [1, 13].

Several recent studies from North America and Western Europe all showed a significant increase of total NTM isolation rates [2-5]. In the study from the Netherlands, the increase was mainly caused by a rise in $M$. avium and $M$. gordonae isolates from pulmonary samples and it was most pronounced in patients $>40$ years old [3]. A study from the UK showed that the increase in NTM reports was mainly in pulmonary specimens and people aged $>60$ years, with $M$. gordonae showing the biggest increase but MAC remaining the most commonly reported species [14]. In Denmark, the rising trend in NTM isolation was less obvious but the incidence of NTM disease had increased, especially in elderly [4].

The NTM species that are cultured from clinical samples differ strongly by region [6]. We found interesting regional differences. Even though the majority of all NTM isolates came from continental Croatia, most of those were species generally considered of low virulence $[1,13]$. In contrast, clinically relevant NTM isolates were significantly more often found in the coastal region of Croatia. The species distribution in pulmonary samples is recorded in Figure 4. Some of the factors that might promote these observed regional differences in Croatia include the climate, rate of urbanization and TB incidence [15]. The urbanized coastal region has wetter and warmer climate and relies on larger municipal water supplies, compared to the more rural, continental part of Croatia where more 
households use well water. Furthermore, the incidence of TB was lower in coastal region $(21.2 / 100,000)$ than in the continental region of Croatia $(30.1 / 100,000)$ in 2006 [10].

Pulmonary disease

We relied solely on microbiologic criteria to assign patients with isolated NTM to three groups probable, possible, and unlikely disease. We used this approach since it was previously shown that microbiologic criteria are highly predictive of disease and are useful for laboratory-based NTM disease surveillance $[8,9]$.

The data observed in this study are consistent with the earlier described epidemiology of M. xenopi infection in Croatia [16]. However, despite the high frequency of $M$. xenopi isolation, M. avium, $M$. intracellulare, and $M$. kansasii were more strongly associated with pulmonary NTM disease compared to $M$. xenopi. This differs from observations in the Netherlands, where $M$. xenopi and $M$. kansasii were more strongly associated with disease than M. avium and M. intracellulare [13], applying the full ATS diagnostic criteria [1]. The background of such apparent regional differences remains unknown.

Taking into account all individuals meeting the microbiologic criteria, we estimated annual incidence of NTM pulmonary disease at $0.60 / 100,000$. However, the number of cases of $M$. gordonae disease is likely overestimated, since it is known to rarely cause true disease $[1,13]$. Discarding all of the $M$. gordonae cases, the annual incidence would be $0.38 / 100,000$. Furthermore, taking into account the probable disease group only, the annual incidence decreases to $0.23 / 100,000$ with most of the cases due to M. xenopi, M. avium, M. intracellulare, M. kansasii and M. abscessus.

The incidence of NTM pulmonary disease in Croatia is low compared to its TB incidence and to NTM data from North-Western Europe. In the Netherlands, the incidence of NTM disease has been estimated at 1.7/100,000 in 2008 [17] while in Denmark the incidence of true disease reached 1.08/100,000 [4]. A study from New Zealand, using methodology similar to ours, estimated pulmonary NTM disease incidence to be $1.2 / 100,000$ and found a majority (79\%) of cases to be women [18]. We found no significant gender differences in NTM pulmonary disease cases (Table 2).

The incidence of TB in Croatia is higher than in North-Western Europe and New Zealand, and Bacillus Calmette-Guerin (BCG) vaccination is still mandatory. This may explain the lower NTM isolation and 
disease rates since it has been speculated that infection with TB and BCG vaccination may provide cross-immunity to NTM infection [19].

We observed that a higher percentage of patients living in coastal Croatia met the defined disease criteria, compared to those living in continental Croatia. Moreover, the estimated annual incidence in coastal region is twice as high as in the continental region. This might be a reflection the species distribution in these two regions but further research is needed to fully understand the observed differences. A recent study in the USA showed that regional environmental factors related to soil and differences in daily evapotranspiration levels are associated with pulmonary NTM disease, but that both host susceptibility and environmental factors should be considered in explaining disease development [20].

The limitation of this study is the lack of clinical and radiological data. The used methodology could cause disease overestimation (e.g. for M. gordonae). On the other hand, disease incidence could also be underestimated in case of having only one sputum sample sent to the laboratory for identification with no follow-up testing. We applied the possible and probable disease criteria to increase the strength of solely using the microbiologic criteria. Also, it is possible that incidence of NTM disease is slightly overestimated given that some of the patients classified as "incident cases" in 2006, might have had NTM isolated prior to the study period. We tried to minimise this error by looking into the available data from the year 2005, and excluding the recurrent cases from the disease incidence calculation.

In summary, we have shown that the NTM species distribution as well as the incidence of pulmonary NTM disease significantly differs between the coastal and continental region of Croatia. NTM pulmonary disease is strongly associated with age and more often affects males, but the burden of disease remains low compared to TB. Annual incidence amounts to $0.60 / 100,000$, or $0.23 / 100,000$ if restricted to probable disease only. The isolation frequency slightly rose throughout the study period. 


\section{REFERENCES}

1. Griffith DE, Aksamit T, Brown-Elliott BA, et al. ATS Mycobacterial Disease Subcommittee; American Thoracic Society; Infectious Diseases Society of America. An official ATS/IDSA statement: diagnosis, treatment, and prevention of neontuberculous mycobacterial diseases. Am J Respir Crit Care Med 2007; 175:367-416.

2. Marras TK, Chedore P, Ying AM, Jamieson F. Isolation prevalence of pulmonary nontuberculous mycobacteria in Ontario 1997-2003. Thorax 2007; 8:661-666.

3. Van Ingen J, Hoefsloot W, Dekhuijzen PNR, Boeree MJ, van Soolingen D. The changing pattern of clinical Mycobacterium avium isolation in the Netherlands. Int J Tuberc Lung Dis 2010; 14(9): 1176-1180.

4. Andréjak $C$, Thomsen $\vee \varnothing$, Johansen IS, et al. Nontuberculous pulmonary mycobacteriosis in Denmark: incidence and prognostic factors. Am J Respir Crit Care Med 2010: 181: 514-521.

5. Martin-Casabona N, Bahrmand AR, Bennedsen J, et al. Spanish Group for Non-Tuberculosis Mycobacteria. Non-tuberculous mycobacteria: patterns of isolation. A multi-country retrospective survey. Int J Tuberc Lung Dis 2004; 8:1186-1193.

6. Marras TK, Daley CL. Epidemiology of human pulmonary infection with nontuberculous mycobacteria. Clin Chest Med 2002; 23:553-567.

7. Daley CL, Griffith DE. Pulmonary non-tuberculous mycobacterial infections. Int J Tuberc Lung Dis $2010 ; 14: 665-671$.

8. Cassidy PM, Hedberg K, Saulson A, McNelly E, Winthrop KL. Nontuberculous Mycobacterial Disease Prevalence and Risk Factors: A Changing Epidemiology. CID 2009; 49(12):124-129.

9. Winthrop KL, McNelly E, Kendall B, et al. Pulmonary Nontuberculous Mycobacterial Disease Prevalence and Clinical features. Am J Respir CritCare Med 2010; 182:977-982.

10. Croatian Health Service Yearbook 2010, Zagreb 2011. Available from: http://www.hzjz.hr/publikacije/hzs_ljetopis/Ljetopis_Yearbook_HR_2010.pdf.

11. The Statistical Office of the European Communities (Eurostat). http://epp.eurostat.ec.europa.eu/. Date last update July 25 2012. Date last accesses: July 25 2012.

12. Kent PT, Kubica GP. Public Health Mycobacteriology. A Guide for the Level III Laboratory. Atlanta, GA, 1985: US Department of Health and Human Services. 
13. Van Ingen J, Bendien SA, de Lange WC, et al. Clinical relevance of non-tuberculous mycobacteria isolated in Nijmegen-Arnhem region, The Netherlands. Thorax 2009; 64:502506.

14. Moore JE, Kruijshaar ME, Omerod LP, Drobniewski F, Abubakar I. Increasing reports of nontuberculous mycobacteria in England, Wales and Northern Ireland, 1995-2006. BMC Public Health 2010; 10:612.

15. Falkinham JO 3rd. Surrounded by mycobacteria: nontuberculous mycobacteria in the human environment. J Appl Microbiol 2009; 107(2):356-367.

16. Marusic A, Katalinic-Jankovic V, Popovic-Grle S, et al. Mycobacterium xenopi pulmonary disease -epidemiology and clinical features in non-immunocompromised patients. J Infect 2009; 58(2):108-112.

17. Van Ingen J. Nontuberculous mycobacteria; from gene sequences to clinical relevance. PhD Thesis. Radboud University Nijmegen, the Netherlands. 2009. Available from: http://webdoc.ubn.ru.nl/mono/i/ingen_j_van/nontmy.pdf

18. Freeman J, Morris A, Blackmore T. Incidence of nontuberculous mycobacterial disease in New Zealand, 2004. N Z Med J 2007; 120:2580.

19. Trnka L, Danková D, Svandová E. Six years' experience with the discontinuation of BCG vaccination. 4. Protective effect of BCG vaccination against the Mycobacterium avium intracellulare complex. Tuber Lung Dis. 1994; 75(5):348-52.

20. Adjemian J, Olivier KN, Seitz AE, Falkinham JO $3^{\text {rd }}$, Holland SM, Prevots DR. Spatial Clusters of Nontuberculous Mycobacterial Lung Disease in the United States. Am J Respir Crit Care Med 2012; 186(6): 553-558. 
Table 1. Non-tuberculous mycobacteria (NTM) isolation frequency in Croatia according to gender, geographic region and microbiologic criteria

\begin{tabular}{|c|c|c|c|c|c|c|c|c|}
\hline \multirow{2}{*}{ NTM species } & \multirow[b]{2}{*}{ Total (\%) } & \multicolumn{2}{|c|}{ Geographic region } & \multicolumn{2}{|c|}{ Gender } & \multicolumn{3}{|c|}{ Microbiologic criteria } \\
\hline & & $\begin{array}{c}\text { Continental } \\
\text { total (\%) }\end{array}$ & $\begin{array}{l}\text { Coastal } \\
\text { total (\%) }\end{array}$ & $\begin{array}{c}\text { Female } \\
\text { total (\%) }\end{array}$ & $\begin{array}{c}\text { Male } \\
\text { total (\%) }\end{array}$ & $\begin{array}{l}\text { Probable } \\
\text { disease* } \\
\text { total (\%) }\end{array}$ & $\begin{array}{l}\text { Possible } \\
\text { disease* } \\
\text { total (\%) }\end{array}$ & $\begin{array}{l}\text { Unlikely } \\
\text { disease* } \\
\text { total (\%) }\end{array}$ \\
\hline M. gordonae & 509 (42.9) & $437(45.5)$ & $72(32)$ & $219(45)$ & $290(41.5)$ & $5(7.7)$ & $29(28.4)$ & $475(46.6)$ \\
\hline M. xenopi & $184(15.5)$ & $108(11.2)$ & $76(33.8)$ & $57(11.7)$ & $127(18.2)$ & $21(32.3)$ & $26(25.5)$ & $137(13.4)$ \\
\hline M. fortuitum & $136(11.5)$ & $121(12.6)$ & $15(6.7)$ & 48 (9.9) & $88(12.6)$ & $3(4.6)$ & $16(15.7)$ & $117(11.5)$ \\
\hline M. terrae & $93(7.8)$ & $89(9.3)$ & $4(1.8)$ & $47(9.7)$ & $46(6.6)$ & $0(0)$ & $4(3.9)$ & $89(8.7)$ \\
\hline M. avium & $42(3.5)$ & $23(2.4)$ & $19(8.4)$ & $24(4.9)$ & $18(2.6)$ & $14(21.5)$ & $10(9.8)$ & $18(1.8)$ \\
\hline M. abscessus & $30(2.5)$ & $26(2.7)$ & $4(1.8)$ & $13(2.7)$ & $17(2.3)$ & $3(4.6)$ & $5(4.9)$ & $22(2.2)$ \\
\hline M. intracellulare & $23(1.9)$ & $16(1.7)$ & $7(3.1)$ & $10(2)$ & $13(1.9)$ & $8(12.3)$ & $1(1)$ & $14(1.4)$ \\
\hline M. kansasii & $10(0.8)$ & $6(0.6)$ & $4(1.8)$ & $4(0.8)$ & $6(0.9)$ & $4(6.2)$ & $1(1)$ & $5(0.5)$ \\
\hline Other NTM & 159 (13.5) & $135(14)$ & $24(10.7)$ & 65 (13.3) & $94(13.4)$ & $7(10.8)$ & $10(9.8)$ & 142 (13.9) \\
\hline Total & 1186 (100) & $961(100)$ & 225 (100) & 487 (100) & 699 (100) & $65(100)$ & $102(100)$ & 1019 (100) \\
\hline $\begin{array}{c}\text { Probable disease* } \\
\text { (\%) }\end{array}$ & 65 (100\%) & $33(51)$ & $32(49)$ & 31 (47.7) & $34(52.3)$ & & & \\
\hline $\begin{array}{c}\text { Possible disease* } \\
(\%)\end{array}$ & $102(100 \%)$ & 77 (75.5) & $25(24.5)$ & $44(43.1)$ & $58(56.9)$ & & & \\
\hline $\begin{array}{c}\text { Unlikely disease* } \\
(\%)\end{array}$ & 1019 (100\%) & 851 (83.5) & $168(16.5)$ & $412(40.4)$ & 607 (59.6) & & & \\
\hline
\end{tabular}

* Possible disease: either two positive sputums, or one positive bronchial lavage (BAL) or brush Probable disease: more than two positive sputum samples; one positive BAL/brush and one or more positive sputum samples. 
Table 2. Demographic characteristics of patients meeting the microbiologic criteria of probable and possible pulmonary non-tuberculous mycobacteria (NTM) disease* per year per 100.000 population in Croatia

\begin{tabular}{|c|c|c|c|c|c|c|c|}
\hline & \multicolumn{3}{|c|}{ Probable Disease* } & \multicolumn{3}{|c|}{ Possible disease* } & \multirow[b]{2}{*}{$\begin{array}{c}\text { Average } \\
\text { population }\end{array}$} \\
\hline Cases & $\begin{array}{c}\text { Value } \\
\text { (percent) }\end{array}$ & $\begin{array}{c}\text { Median } \\
\text { age }\end{array}$ & $\begin{array}{l}\text { Annual } \\
\text { incidence }\end{array}$ & $\begin{array}{c}\text { Value } \\
\text { (percent) }\end{array}$ & $\begin{array}{c}\text { Median } \\
\text { age }\end{array}$ & $\begin{array}{l}\text { Annual } \\
\text { incidence }\end{array}$ & \\
\hline All cases & $65(100)$ & 66 & $0,23 * *$ & $102(100)$ & 65 & $0,38 * *$ & 4436265 \\
\hline \multicolumn{8}{|l|}{ Gender } \\
\hline Female & $31(47.7)$ & 66 & $0,20 * *$ & $44(43.1)$ & 62 & $0,33^{* *}$ & 2297905 \\
\hline Male & $34(52.3)$ & 64.5 & $0,21 * *$ & $58(56.9)$ & 65.5 & $0,37 * *$ & 2138360 \\
\hline \multicolumn{8}{|l|}{ Age } \\
\hline $0-9$ & 0 & 0 & & $4(3.9)$ & 4.5 & 0,18 & 432,458 \\
\hline $10-19$ & 0 & 0 & & $4(3.9)$ & 14 & 0,15 & 517,389 \\
\hline $20-29$ & $2(3.1)$ & 21 & 0,07 & $2(2)$ & 27 & 0,07 & 607,393 \\
\hline $30-39$ & $2(3.1)$ & 33 & 0,07 & $5(4.9)$ & 37 & 0,17 & 597,061 \\
\hline $40-49$ & $3(4.6)$ & 49 & 0,09 & $6(5.9)$ & 44.5 & 0,19 & 641,701 \\
\hline $50-59$ & $16(24.6)$ & 56.5 & 0,51 & $20(19.6)$ & 55.5 & 0,63 & 632,411 \\
\hline $60-69$ & $15(23.1)$ & 66 & 0,65 & $25(24.5)$ & 66 & 1,08 & 461,805 \\
\hline $70-79$ & $17(26.2)$ & 73 & 0,89 & $28(27.5)$ & 74 & 1,46 & 383,530 \\
\hline $80+$ & $8(12,3)$ & 85 & 1,12 & $8(7.8)$ & 82 & 1,12 & 143,306 \\
\hline Unknown & $2(3.1)$ & & & 0 & & & \\
\hline $50+$ & $56(86.2)$ & 68 & 0,69 & $81(79.4)$ & 68 & 1 & $1,621,052$ \\
\hline \multicolumn{8}{|l|}{$\begin{array}{c}\text { Geographic } \\
\text { location }\end{array}$} \\
\hline Continental & $33(50.1)$ & 69 & $0,17^{* *}$ & $77(75.5)$ & 60 & $0,44 * *$ & $2,971,550$ \\
\hline Coastal & 32 (49.9) & 64.5 & $0.35^{* *}$ & $25(24.5)$ & 68 & $0,25^{* *}$ & $1,464,715$ \\
\hline
\end{tabular}

* Possible disease: either two positive sputums, or one positive bronchial lavage (BAL) or brush Probable disease: more than two positive sputum samples; one positive BAL/brush and one or more positive sputum samples.

** $\quad$ Age standardized incidence rates 
Jankovic, M., Samarzija, M., Sabol, I., Jakopovic, M., Katalinic Jankovic, V., Zmak, L., Ticac, B., Marusic, A., Obrovac, M., van Ingen, J., 2013. Geographical distribution and clinical relevance of non-tuberculous mycobacteria in Croatia. The International Journal of Tuberculosis and Lung Disease 17, 836-841. doi:10.5588/ijtld.12.0843 - Accepted Version

Figure 1. Total number of Mycobacterium spp., Mycobacterium tuberculosis and pulmonary nontuberculous mycobacteria (NTM) isolates submitted to the National Reference Laboratory during the study period.

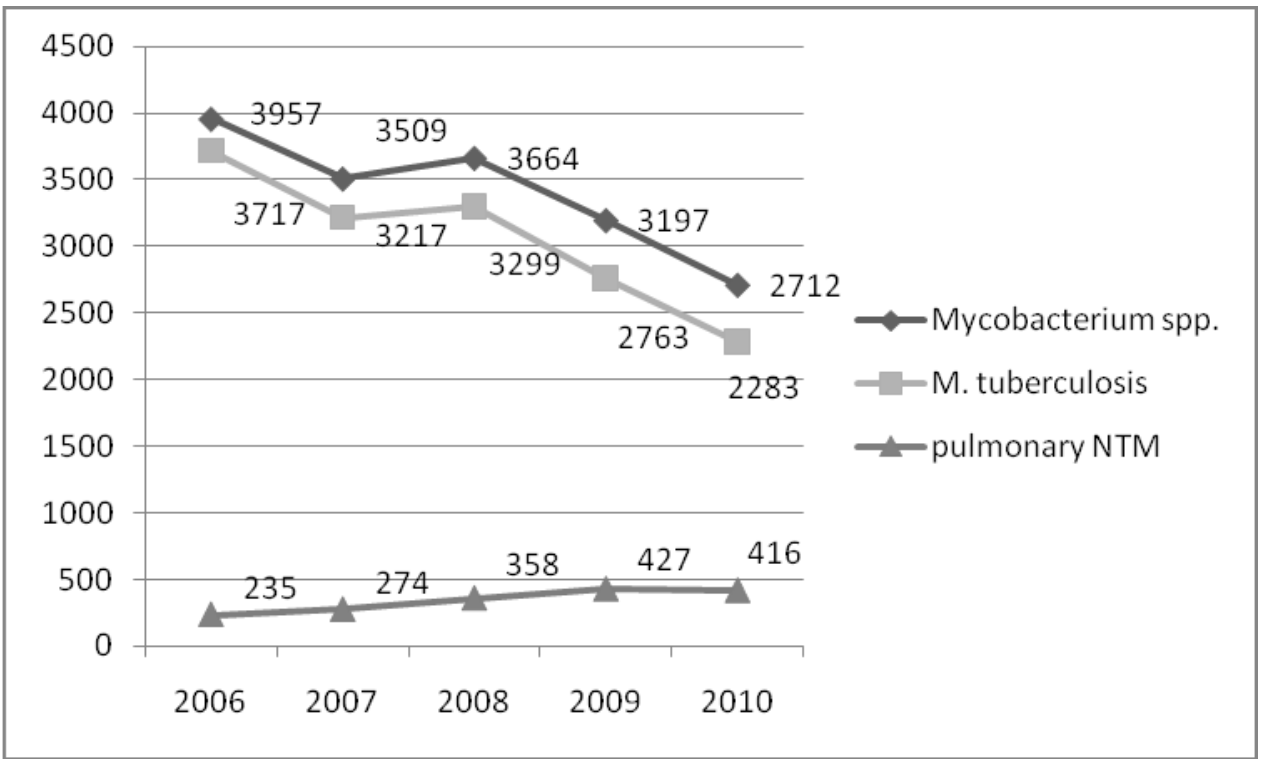


Jankovic, M., Samarzija, M., Sabol, I., Jakopovic, M., Katalinic Jankovic, V., Zmak, L., Ticac, B., Marusic, A., Obrovac, M., van Ingen, J., 2013. Geographical distribution and clinical relevance of non-tuberculous mycobacteria in Croatia. The International Journal of Tuberculosis and Lung Disease 17, 836-841. doi:10.5588/ijtld.12.0843 - Accepted Version

Figure 2. The distribution of non-tuberculous mycobacteria (NTM) species isolated from pulmonary samples in the coastal and continental region of Croatia

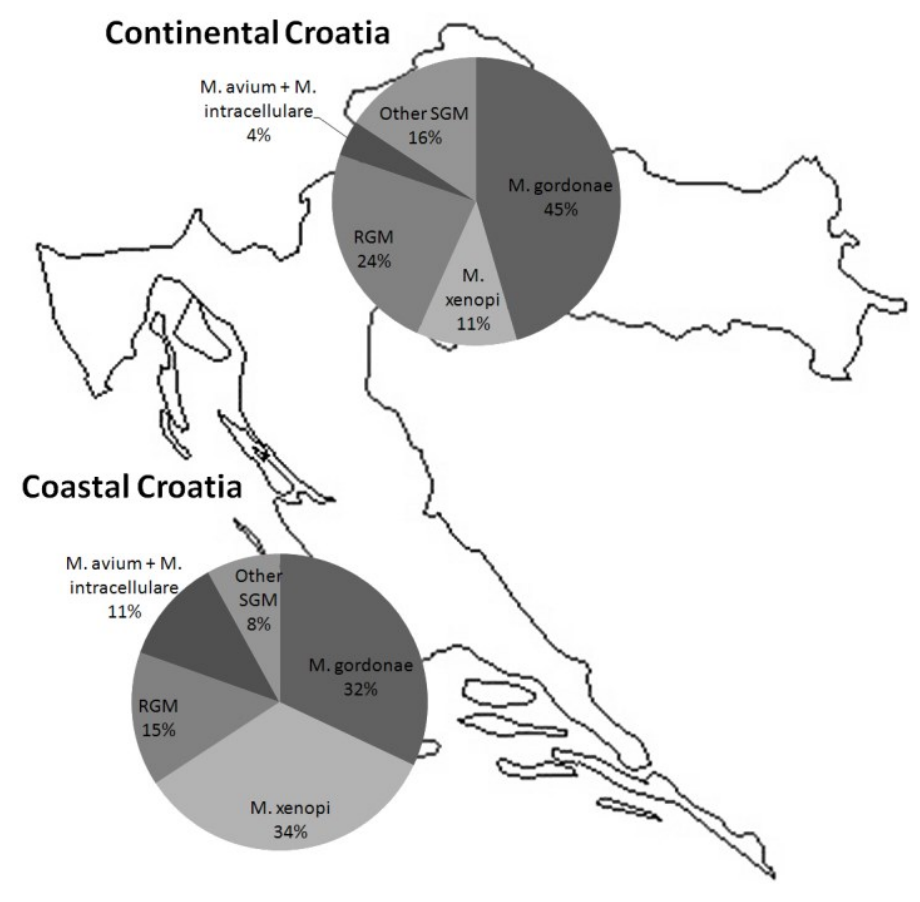


Jankovic, M., Samarzija, M., Sabol, I., Jakopovic, M., Katalinic Jankovic, V., Zmak, L., Ticac, B., Marusic, A., Obrovac, M., van Ingen, J., 2013. Geographical distribution and clinical relevance of non-tuberculous mycobacteria in Croatia. The International Journal of Tuberculosis and Lung Disease 17, 836-841. doi:10.5588/ijtld.12.0843 - Accepted Version

Figure 3. Crude non-tuberculous mycobacteria (NTM) isolation frequency rate per 100.000 population stratified by age and gender

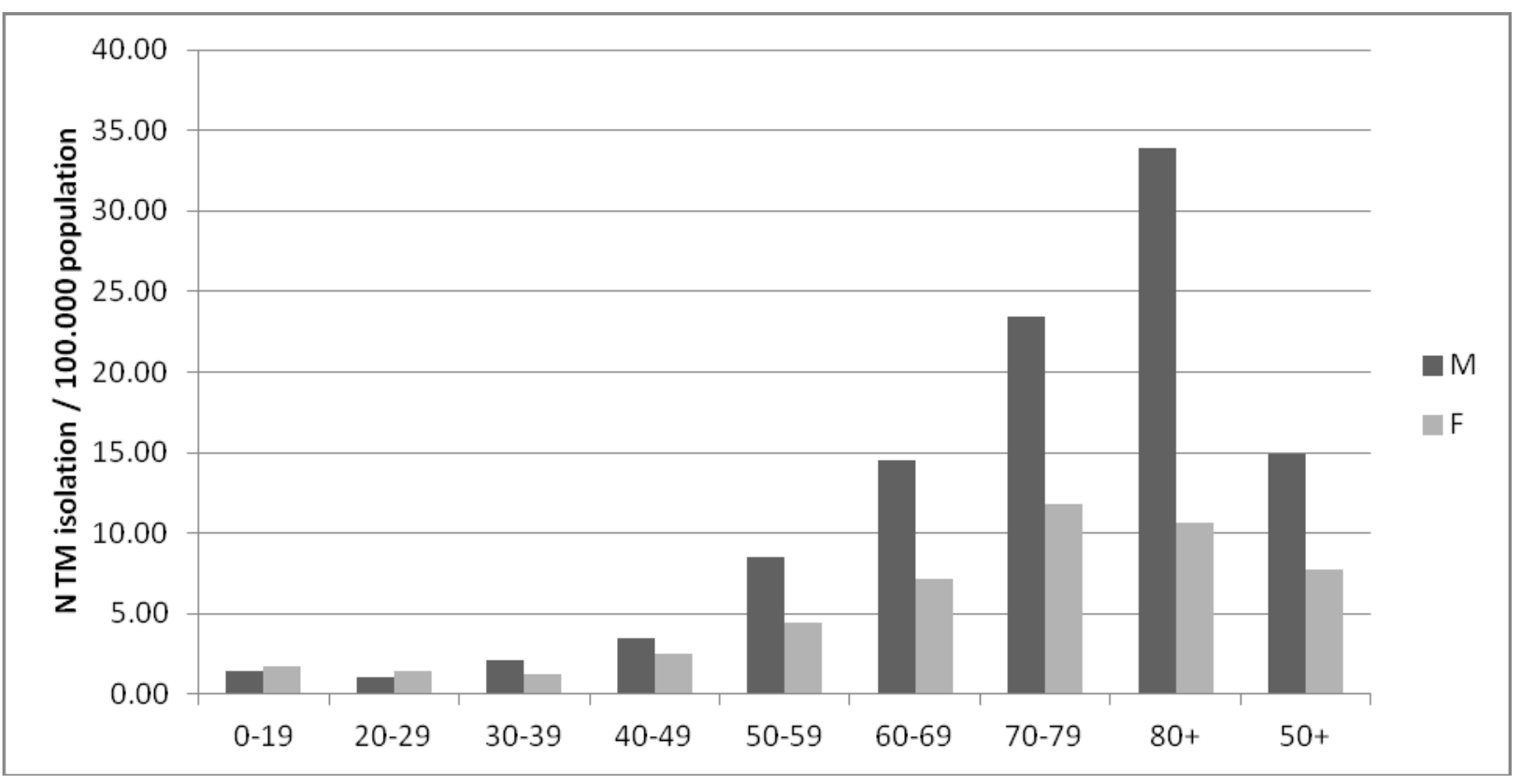

$\mathrm{M}$ - male; F - female 
Jankovic, M., Samarzija, M., Sabol, I., Jakopovic, M., Katalinic Jankovic, V., Zmak, L., Ticac, B., Marusic, A., Obrovac, M., van Ingen, J., 2013. Geographical distribution and clinical relevance of non-tuberculous mycobacteria in Croatia. The International Journal of Tuberculosis and Lung Disease 17, 836-841. doi:10.5588/ijtld.12.0843 - Accepted Version

Figure 4. Isolation frequency rate of the most common non-tuberculous mycobacteria (NTM) species in Croatia per year per 100.000 population
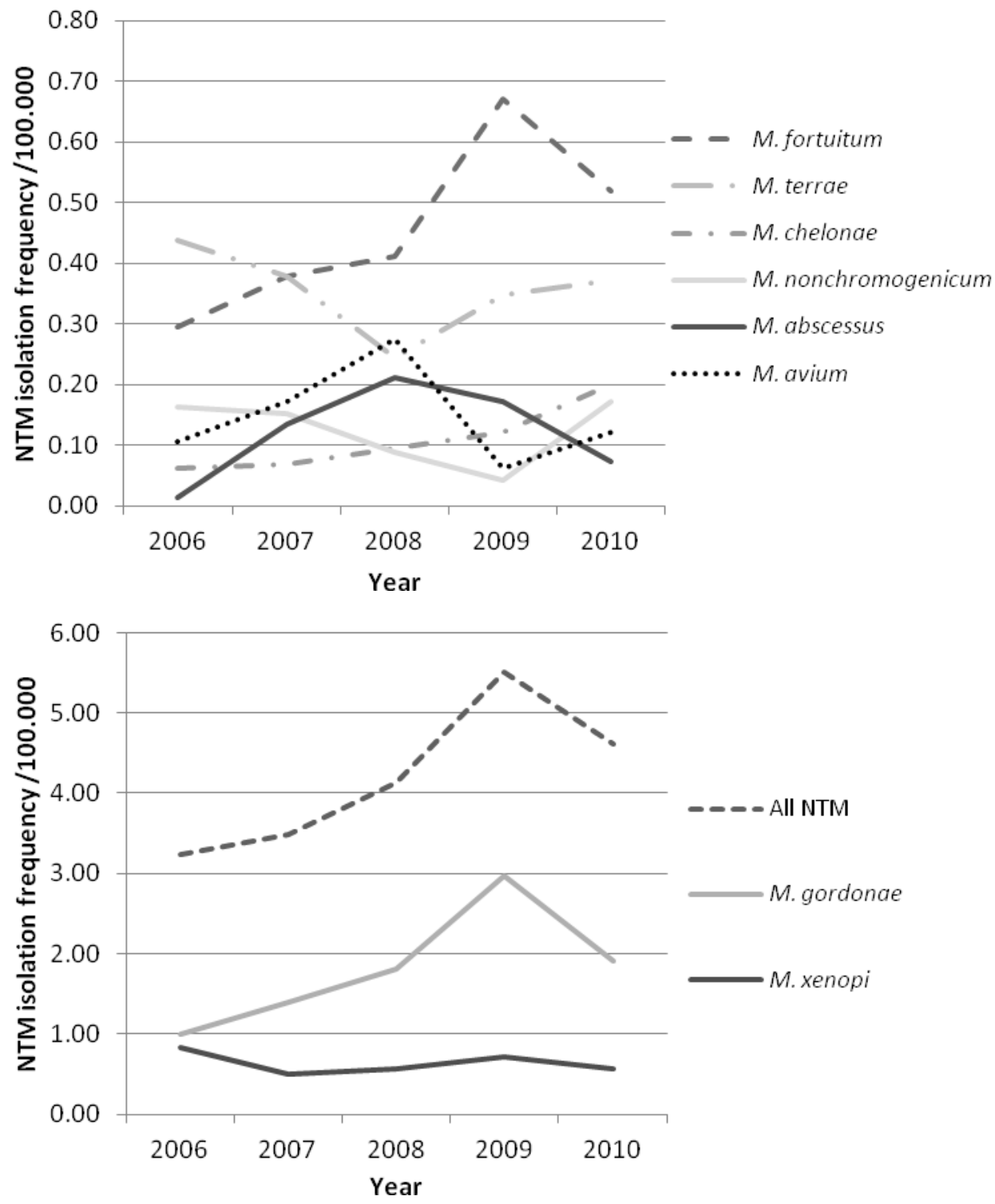